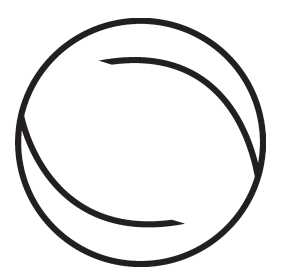

\title{
Seeing More and Seeing Differently: Sensemaking, Mindfulness, and the Workarts
}

\author{
Daved Barry and Stefan Meisiek
}

Daved Barry

Copenhagen Business

School, Denmark

Nova SBE, Portugal

Stefan Meisiek

Copenhagen Business

School, Denmark

Nova SBE, Portugal
Organization

Studies

31(12): 1-26

ISSN 0170-8406

Copyright (C) The

Author(s), 2010.

Reprints and

permissions:

http://www.sagepub.

co.uk/journals

permissions.nav

\begin{abstract}
The past years have seen a marked rise in arts-based initiatives in organizations, a field we term the workarts. In this paper, we review the workarts in light of sensemaking theory, and especially the role of mindfulness within it. We propose that the workarts foster mindfulness by directing attention away from immediate work concerns and towards analogous artifacts. We identify three distinctive workarts movements - art collection, artist-led intervention, and artistic experimentation. In each movement, we find analogous artifacts that defamiliarize organizational members' habitual ways of seeing and believing, enabling them to make new distinctions and to shift contexts: to see more and see differently. Our review raises a number of questions for the workarts in particular and research on analogical artifacts in general.
\end{abstract}

Keywords: art, analogy, mindfulness, sensemaking

If collective mindfulness - defined as 'the capacity of groups and individuals to be acutely aware of significant details, to notice errors in the making, and to have the shared expertise and freedom to act on what they notice' (Weick et al. 2000: 34 ) - is as precious a resource for organizational survival as sensemaking scholars say (Tsoukas and Chia 2002; Levinthal and Rerup 2006; Weick and Sutcliffe 2006), then how might it be cultivated? To date the answer has been to improve the quality and quantity of attention directed towards work processes and the organizational environment: deliberately refining existing categories with new information, continuously drawing out new distinctions from the stream of organizational events, and creatively reframing contextual understandings in the face of an ever-becoming world (Langer 1989; Weick et al. 1999).

A distinctively different answer to the mindfulness question, or so we argue in this paper, involves analogous artifacts, particularly those which possess artistic attributes such as originality, subversion, deconstruction, redirection, symbolization, quotation, parody, allusion, and allegory (Davies 2006). Analogous artifacts are objects and performances that induce but do not dictate analogical considerations. For our purposes here, we consider analogous artifacts as evocative representations that do not serve immediate organizational purposes, yet invite inquiry and reflection by defamiliarizing organizational members' habitual conceptualizations (Schein 2001). They are related to, but distinguishable from, 'analogically 
mediated inquiry' (Barry 1994, 1996; Meisiek and Barry 2007), a process in which analogically suggestive representations around organizational concerns are deliberately formed in order to open up and enrich the problem-solving process. For example, company members might make models that depict a competitive threat. Perhaps one of the sculptures is a blue, many-angled house: the 'Competitor's Blue House'. In a guided inquiry process, the members might analogically ask how a blue threat compares to a red threat, which of the competitor's angles seem most dangerous, and what kind of being lives in such a house. While analogous artifacts are a core part of such inquiry processes, they can, and often do, operate in unplanned and autonomous ways.

Analogous artifacts similarly resemble 'boundary objects' (Carlile 2002) in that they cross multiple domains of knowing. But unlike boundary objects, they do not necessarily bridge two distinct worlds the way, say, a prototype might connect marketing and engineering departments. Rather, they are more akin to Turkle's (2007) 'evocative objects', where the artifact is potentially meaningful and analogous, where the analogical target is amorphous or unknown, and where the analogical source is complexly interpretable. Consonant with Cornelissen (2004), there is no faithful structural mapping from source to target domain in order to transfer specific knowledge from one domain to another. Instead, the analogical artifact invites 'inference-making that transcends the similarities at hand' (Meisiek and Barry 2007: 1807).

A classical example from the art world is Magritte's painting 'Ceci n'est pas une pipe' (This is not a pipe). The picture shows a mundanely rendered pipe and the title painted on the canvas, immediately suggesting that what we see is not what it seems. Such artifacts create sensible variance around our usual ways of seeing, calling attention to the unquestioning nature of our working with images and objects. This variance consists of interactive openings of the physical senses (e.g. increasing attention to the painterly qualities as the viewer works on Magritte's riddle) and conceptual senses (e.g. questioning one's fine art categories). By calling attention to an analogous world that temporarily transcends immediate concerns, the artifact fosters mindfulness with a playful orientation, where new possibilities can imaginatively arise as the boundaries between 'artifact' and 'analogy' blur, and our habitual understandings are drawn into doubt.

As the Magritte example suggests, the production of analogous artifacts in society is a central feature of the arts (e.g. Heidegger 1975; Gadamer 1986; Shklovsky 2004). The arts use artifacts and analogical processes to make our familiar sensemaking resources unfamiliar, to discover new ways through them, and to make them more deeply meaningful. It is this power to defamiliarize that gives the arts their ability to vibrate, resonate, and enliven (Shklovsky 2004). For example, Duchamp's 'Fountain' (a urinal exhibited in the Pompidou Museum) is considered great art because the choice of an utterly banal object and the act of its placement dramatically challenged almost every assumption made by the traditional arts as well as the basic workings of the art industry.

Given the arts' involvement with analogous artifacts and the potential for analogous artifacts to foster collective mindfulness, we turn to an arena where art, artifacts, and work meet: the workarts, as we have come to term the field. The term 'workarts' takes the term 'artwork' and reverses it so as to emphasize the 
work that art does at work. It denotes art as it occurs in the workplace - whether the factory floor, the education ministry, board rooms, or in industry development. As such, the term highlights the difference between the interests of fine art institutions and organizational interests in art. The workarts are about making or collecting art for the workplace in an attempt to challenge and improve the work, rather than managing the production, distribution, and presentation of art. Because the workart's production and use of analogous artifacts is typically directed at creating organizational influence, it represents a potentially good arena for studying the ways in which analogous artifacts might foster mindfulness within organizational settings.

In the sections that follow, we first present a theorizing discussion of mindfulness and analogous artifacts; in particular, we take up Ellen Langer's (1989) ideas of distinction making (seeing more) and context shifting (seeing differently). We then employ these concepts in a review-based study of analogous artifacts within the workarts, describing how mindfulness is fostered within three general workart practices: art collection, artist-led intervention, and artistic experimentation. The paper closes with a discussion of how analogous artifacts might affect sensemaking across different organizational environments and recommendations for future research in this area.

\section{Seeing More and Seeing Differently}

According to Langer and Moldoveanu (2000: 1-2), mindfulness is best understood as a process where a certain alertness prevails: "The subjective "feel" of mindfulness is that of a heightened state of involvement and wakefulness or being in the present.' It involves iterations of analysis and synthesis across seeing more (distinction making), and seeing differently (context shifting):

We can look at the world and ask how things differ (make distinctions) or how they are the same (make analogies). The first approach results in the creation of new categories, the second usually involves shifting of contexts, both of which we have described as mindful activities. (Langer 1989: 130)

With respect to distinction making and our tendency to mostly 'see what we believe' (Weick 1995: 133), sensemaking theorists suggest that we prepare ourselves by mindfully attending to weak, diverse, and disparate environmental cues (Levinthal and Rerup 2006; Rerup 2009). We are advised to notice and see more both comfortable strong cues and discomfiting weak ones (Weick et al. 2005).

The literature suggests a number of ways to fruitfully see more. One is to look farther - look in the same direction (both forwards and backwards) but look harder, wider, higher, and deeper (Gavetti and Levinthal 2000). Here we find areas like weak signal thinking (Ansoff 1975) and the scenario literature (Wilson and Ralston 2006), both of which give us ways to look further afield. There is also the 'look closer' literature, such as Rerup's (2009) 'attention triangulation' process, where organizational stakeholders are urged to focus on ambiguous results that lie between clear success and clear failure. Closely related to these 'sensitive search' strategies is the advice to pay attention to cues that are odd, unfamiliar, and on the border in some way. Peripheral-vision 
thinking fits here (Day and Schoemaker 2004), where the idea is to deliberately bring in not-so-noticeable things to look at and find explanations for those things. Peripheral vision is usually disconfirmatory in some way. It may suggest that we are not looking as we should, or perhaps that we are looking in the wrong place altogether.

All of these strategies are grounded in a notion of requisite variety, where we are encouraged to hold a lot and make it familiar even if we don't need it in this moment ... just in case. Extending this to the workarts, we propose that the analogous artifacts involved there can also foster mindful distinction making, but in an indirect way. The analogous artifact creates a state of absorptive attention which in turn can raise our attention to detail (Tsoukas and Chia 2002). For example, police officers at Scotland Yard train their observation skills by appreciatively looking at pieces of 19th-century art. The assumption is that the observational skills obtained with the artworks will help the officers make better sense of crime scene photos (Medical Yale 2006). While at first glance the officers find the paintings simple and unsuggestive, with time and practice they come to see more details, patterns, and develop new ways of looking.

Thus, paying attention to the very act of looking and seeing can help organizational members explore and reveal the concepts that they hold. The analogous artifact helps us notice something that is utterly familiar and attended to, yet notice it in a way that is provocatively different than before - not just through comparisons to newly gained information, but by questioning the resolute matter-of-factness of our ready-at-hand schemas.

With respect to 'context shifting', the aim is to see differently rather than to see more. We analogically compare understandings across contexts to see if they might help us change our perspective. Langer (1989: 131) gives the example of developers who analogously compared a hospital to a hotel, resulting in a hospital design that served more complex needs. The difficulty here is to mindfully choose and explore analogies that can spark generative insights. Analogies and metaphors tend to 'go dead' when used frequently and mindlessly (cf. Lakoff and Johnson 1980), even as their recurrent use reaffirms the identity of a group. This was found for example in the analogies used to describe teamwork across cultures (Gibson and Zellmer-Bruhn 2001).

Fresh and intriguing analogies might bring mindfulness back and help shift the context under scrutiny. In the Rumpelstiltskin organization (Smith and Simmons 1983), for example, employees used the fairy tale to reframe their organization after its leader's vision was failing and budget cuts left little maneuvering room. Describing their environment as the King, service providers as Rumpelstilskin, mid-level administrators as the Father, and key staff as the Daughter, the fairy-tale's storyline served as a sensemaking device for changing understandings about what had happened over the prior months. The analogy enabled conversations between board and employees that would have stalled if the organizational issues had been discussed directly, eventually resulting in the leader's dismissal.

Often, however, others introduce analogies with the intent of giving sense rather than questioning it (Gioia and Thomas 1996; Weick et al. 2005). Newspapers compare the work of entrepreneurial leaders to the hero's journey 
(Nicholsen and Andersen 2005). Political leaders take analogies from history to frame current events (Dyson and Preston 2006). Managers attempt to support change initiatives in similar ways (Gioia and Chittipeddi 1991). And entrepreneurs try to build legitimacy around their highly uncertain endeavors through analogies, e.g. the case of the 'information superhighway' and the question of what kinds of restaurants and gas stations will populate it (Hill and Levenhagen 1995). All of these are declarative attempts to inform and constrain the identity of organizational members (Gioia and Thomas 1996; Weick et al. 2005).

Comparatively, the analogies evoked by workart artifacts tend to dis-inform and unconstrain. They promote context shifting in indirect ways. In place of the advice 'attention needs to be made more stable (i.e. norms and routines must specify and reward attention to intended objects) and more vivid (i.e. distractions need to be removed)' (Weick and Sutcliffe 2006: 517), the workarts do the opposite - attention to routine is destabilized, and vividness is cultivated by working with the distracting and different. To accomplish this, the workarts evoke analogies with the help of artifact cues that prime, edit, or trigger sensemaking (Weber and Glynn 2006). Attention is turned towards the analogous artifact in question with a sense of reflection and inquisitiveness. The mindful attention that subsequently arises happens because one wants to look and focus (rather than being obliged to), and looking and focusing take on a hedonic and lively character rather than an emptying and calming one. Ellen Langer, herself a visual artist in addition to being an experimental social psychologist, notes as much as she comments on a failed attempt to combine her paintings and photos of her household rooms in an old window frame:

I didn't feel dejected at my failed attempt: I was too aware of the enlivening aspect of simply having created the piece. I'm still excited when I think about changing the paintings in the window. I don't know if it will work, but that is part of the fun. In fact, if I knew for certain that a new idea would work, constructing it would probably seem tedious instead of exciting. (Langer 2006: 17)

Seeing more and seeing differently, though distinct, can cross inform one another, particularly within the ambiguous interpretive space that the workarts create. As one creates more distinctions, possibilities for context shifting might open up. Looking at paintings to improve pattern recognition in crime scene photos might at first improve officers' attention to detail, but with time, the officers' ideas about representing crime scenes might shift as they examine the artistic intentions behind the paintings and later come to question the facticity that crime scene photos usually suggest. Concomitantly, as context shifting occurs, new pathways for distinction making can open up. By making their environment the King rather than their CEO, the Rumpelstiltskin organization first changed contexts, which in turn led to new distinctions around what constituted effective and ineffective leadership.

\section{Reviewing the Workarts}

In the previous paragraphs we have identified and discussed ways in which sensemaking and mindfulness might differ when channeled towards analogous 
artifacts. Here we more closely consider these ideas through a review of the workarts. We begin by describing the sources we used for our review (detailed in the Appendix).

To identify the contents and limits of the workarts we undertook a formal literature search, gathering and examining academic articles, reports, and books dealing with arts and business. We also reviewed the mailing list entries of AACORN (Arts, Aesthetics, Creativity and Organization Research Network; www.jiscmail.ac.uk/aacorn) from 2003 to 2009, where a community of artists, academics, and consultants discuss theoretical issues, practices, and recent achievements regarding arts and business initiatives.

As it turned out, most texts dealt with art management and art markets; very few authors wrote about art processes as they affect organization. We also found few empirical and/or systematic studies of workart processes and effects. In contrast, the workarts have been amply described in opinion pieces, popular press articles, and books. Taken together, however, the broadly available sources provided a picture of how the field has developed over time.

To compensate for the scarcity of reliable published sources, we drew on a number of unsystematic observations and conversations. We followed a wide range of workart initiatives, took part in some as academics, and wrote down what we had experienced. On occasion, we invited workarts practitioners to academic conferences to discuss what they do. In these contexts we talked with them about their interests in the area, their experiences, and their practices.

Despite extensive data gathering efforts in Europe, North America, and Australasia, our data remain only partially representative. Early on it became clear to us that there are a great many unreported workarts initiatives, and that the sources we gathered are just the proverbial tip of the iceberg.

There have long been art-interested individuals in politics and organization art played a large role in renaissance endeavors and leaders have collected art for themselves throughout recorded history. While these constitute beginnings of a sort, we believe that it is modern art and organization that have significantly progressed the workarts - hence our coverage from the 1950s on. We subsequently compared individual workart initiatives to one another. We looked at the role that art played in various organizations, the level of involvement of organizational members, the degree to which professional artists took part, and their purported effects. The purpose of these comparisons was to gain a more fine grained image of uses and trajectories.

We then coalesced our texts, observations, and conversations into a typology consisting of three broad arts-based initiatives: art collection, artist-led intervention, and artistic experimentation. The typology describes how art became workart when it moved from artists exhibiting, performing, and promoting their work under corporate patronage to including art as a means for organizational members to develop mindfulness. Over time, the workarts have shifted from being a peripheral presence to one that works experimentally and mindfully with core organizational processes. We arrived at this typology after trying to organize the field by art media, degree of employee participation, and historical development. In the end we chose the artworks-artists-artistry framework because it seemed to have greater categorical clarity and theory-building potential than the others. 


\section{Art Collection}

Common sense holds that a well-crafted, thought-provoking piece of art may edify or irritate, and in this way reaffirm or provoke the questioning of long-held beliefs. Art pieces that curators, critics, and gallery owners regard as powerful in this regard gain value and become the preferred stock of art museums and private collections (Wijnberg and Gemser 2000). The idea of art as precious seems to feed a tendency among powerful people to collect and surround themselves with it, and managers are no exception (Jacobson 1993). But can corporate collection help organizational members make new distinctions and challenge all-too-familiar perspectives?

At first glance corporate art collecting seems to be more about impressing stakeholders rather than defamiliarization. Since the 1930s, when Thomas J. Watson, founder of IBM, redefined corporate art collecting as a strategic activity that should mutually benefit art and business, the wish for personal aggrandizement, organizational prestige, long-term investment, and decoration of the work environment have all resulted in substantial corporate art collections (Jacobson 1993). From a mindfulness perspective though, such collections may in fact impoverish organizations, particularly as artworks become commodified, separated from their potentially meaning-enhancing properties, and ultimately go unnoticed (Martorella 1990; Wu 2002).

But as managers have sought ways to make organizational members more open-minded and innovative, a number of collectors have turned to their art collections as a possible resource. With this change in collectors' expectations has come a shift in collecting practice. Up until the 1990s top managers almost always administered their own corporate art collections. Since then, most collections have been handed over to professional corporate curators with legitimacy and networks in the art world. The curators choose the artworks and organize their placement throughout the company based on managerial expectations of their effects (Behnke 2007). We can distinguish between collection practices that are intended to lead to distinction making or context shifting.

Distinction Making. Where organizational members are trying to see more in their work processes and the environment, collectors may attempt to stimulate distinction making. At Spring Mills, for example, CEO Scotese (1978: 21-22) justified his collecting with the idea that

art hones our perception and sensitivities so that we have a keener awareness of our business environment. ... There are obvious benefits for a manager in a textile business to immerse himself in the arts. Spring Mills lives and dies, at least figuratively, on the whims and vagaries of color, texture, pattern, tastes and styles.

Collectors aiming for distinction making may choose which art to buy based on the work processes of the organization. Deutsche Bank, for example, 'started collecting "works on paper" due to its close relationship with money, stocks, bonds; all things on paper' (Made 2004: 7). When work processes moved towards digitalization, the art collection shifted as well, extending to electronic art media. Managers there see the collection as an expression of the culture and identity of the organization. At the same time, ever new and rotating exhibits are thought to help people continuously notice more in what they were already doing (Made 2004). 
At the border between distinction making and context shifting are collections intended to provoke and irritate employees rather than reassure them. For example, managers at EA Generali, an Austrian insurance company, wanted their corporate art collection to spread 'creative unrest' throughout the company (Breitwieser 1995). Such unrest is particularly evident in the collection strategy of Mads Øvlisen, former CEO of Novo Nordisk, a Danish pharmaceutical company. He went on a personal quest to acquire 'difficult' artworks from unknown artists. He then saw to it that the works were exhibited throughout Novo Nordisk. He hoped that the art would make people stop and think, and to start asking questions about themselves, their ways of noticing things, and their work (Aunstrup et al. 2000). Many employees found the works appalling and controversy regarding the program filled the workplace. Nevertheless, some years later when Øvlisen retired and workers were given the opportunity to move the art elsewhere, they declined, stating that while they still didn't like the art, it had become a symbol of being able to undertake weird projects (personal communication with Novo Nordisk employees).

When an art collection is deliberately and continuously challenging, as in the Øvlisen case, distinction making might happen through the vibrant antitheses that result. By not stating a clear aim, Øvlisen left it up to his employees to explain what they liked or disliked about the art on their walls. Preferences, emotion, and appreciation became discussable, and this informed how they saw objects and processes closer to their actual work. But only for a time. When the art became a symbol of the culture at Novo Nordisk, it became affirmative rather than disconfirmative, and ceased functioning as art in its upending and challenging form.

Context Shifting. When artworks are not purchased to help or push employees to notice more, but to challenge the status quo and to stimulate questions and reflections around existing perspectives, they can potentially lead to context shifts. To continue the earlier example, when Deutsche Bank acquires another bank, its managers signal change and 'mark their territory' by taking down the acquired bank's artworks and replacing them with new exhibits from the Deutsche Bank collection (Made 2004). Nissley (1999) studied such attempts at sensegiving when he looked at how the art collection of a North American bank changed over several decades, finding that disruptive changes in management were reflected in changes of the art on display. Changes from naturalistic representations of animals and landscapes to abstract works, for example, signaled a new notion of what and how the bank should be. In this way some managers view their art collection as a way to symbolize a particular time and to signal change. The art gives organizational members analogical cues for what management wants them to feel, be, and act like (Craft 1979).

Thus the adding or changing of the art in a work environment can potentially be viewed as a changing of the guard - as a declarative attempt to inform and constrain the identity of organizational members (Gioia and Thomas 1996). However, while attempts to influence organizational identity tend to be closely guided - for example, in private meetings with stakeholder groups - the influence conferred by corporate art collections is more amorphous. This is because the artworks were not explicitly created to represent the organization. It is the 
act of choosing them and their placement in organizations that underlines a change effort, and may lead to context shifts.

For distinction making and context shifting to occur, corporate art collections rely on the willingness of organizational members to actively engage with them; context shifting in particular requires that they interpretatively play with the artistic content. Organizational members have to identify and appropriate a piece of art for themselves. It is also beyond a manager's ability to determine how employees might interpret such artworks. Many might ignore the artworks on the walls, seeing them as more of a nuisance than as a chance for sensemaking. From our various interviews and observations, it is evident that many employees quickly stop noticing and forget that the art is even around. On the whole then, we conclude that corporate art is more likely to provide decoration, unless more active measures are taken to 'put it to work'.

\section{Artist-led Intervention}

A second development in the workarts began when managers brought artists, rather than artworks, into the workplace to catalyze new perspectives. This opportunity arose in part because some artists began making economic processes a focus of their work (Velthuis 2005).

From 1970, the Artist Placement Group in the UK strove to relocate art making into organizational life by arranging artist-in-residence projects (Walker 1995; Ferro-Thomsen 2005). The artist-organization pairings were meant to provide artists with access to the problems and realities of industrialized societies, along with possibilities for sponsorship. With this, artists began moving organizations towards the methods and interpretive perspectives of art. Today, artist groups like Orgacom, Demokratisk Innovation, Acces Local, or Reinigungsgesellschaft work mostly on the conceptual level with organizations (Velthuis 2005). The resulting artworks essentially stand in for the conceptual development and progress made during the process. While the artists welcome beneficial organizational outcomes, these are by no means the primary aim of their projects. Rather, the art community remains the sought-after judge of the artwork's worth.

An example is the Product and Vision project conducted by Mari Brellochs and Henrik Schrat (2005). They brought together a number of European artists to create works around a German publishing house. The art projects were coordinated with the managing directors and financed by a public source. The final works of the participating artists were exhibited in an art gallery. On opening night, employees of the publishing house came to experience the artworks with mixed reviews. While the artworks met the standards of the art community, the employees questioned whether replacing the corporate flags with ones saying 'Ohh!', or cabbage plants growing under artificial light ('money doesn't grow on trees after all') had anything to do with their workplace. The physical distance from the artists, the formal exhibition space in off-site premises, and the works' concern with the approval of the professional arts community left organization members little space for work-related distinction 
making or context shifting. The analogous artifacts were too far removed from their organizational life.

Distinction Making. To bring the artists and their defamiliarizing work with economic relationships closer to organizational concerns, managers started to invite artists to explore work processes and their environment together with organizational members. With this, we see artists bringing interpretative schemata to the organization that are decidedly different from corporate ways of perceiving and doing.

One of the first well documented steps in this direction was the decade long artist-in-residence project at the Xerox Parc R\&D facility (Harris 1999). A group of new media artists was invited to work alongside Xerox product developers. The artists and product developers shared space and emerging technologies, but worked with them in different ways. The product developers were especially surprised by the research methods of the artists. The artists seemed to follow different associative paths, looking for evocative cues and ignoring functionalist ones. An example is 'The Road Not Taken' project by artist Stephen Wilson. In 1994, Wilson was paired with two researchers, Jock Mackinlay and Polle Zellweger, from the Hypermedia and User Interface Group. After showing their latest work to each other, reading articles about each others' interests, and discussing possible avenues for cooperation, Wilson, Mackinlay, and Zellweger decided to work with searches on the World Wide Web, which was in its infancy then. Wilson proposed a Web server that would facilitate searches and also constantly throw up text and images of pages missed.

The Road Not Taken also was a metaphor. It used Internet choices to refer to life choices. It reflected on the fact that people often speculate about what life would have been like if they had made other choices - the 'what if' question that is perennially part of human experience. It also hopefully would induce people to think about the human condition of having only one life to live. (in Harris 1999: 200)

The idea got Mackinlay and Zellweger to think differently about searches on the World Wide Web. With this new distinction between search hits and the value of near misses, Zellweger suggested that the server could also provide glimpses of resources potentially available in addition to presenting what was missed.

Although Xerox eventually shut the project down, inviting artists to spend time and perform in organizations remains a popular managerial practice. For example, Miha Pogacnik, Paul Robertson, Benjamin Zander, and John Cimono's 'Creative Leaps' group regularly give seminars and performances on the relationship between leadership and music. Importantly, in all of these engagements the artist becomes center-stage. She talks about her art as others look on, watching her artist's gaze. With this, the artist's sensemaking becomes a resource, something that organizational members might consider, and may help them to make new distinctions. Tsoukas and Chia (2002), drawing on Bergson, point to art as a means for perceiving the unnoticed and overlooked. By following the artists' understandings and interpretative moves, organizational members might thus notice more about their work and appreciate its dynamic complexity.

Distinction making may become more active when employees are learning artistic sensibilities first hand, rather than co-inhabiting space or listening to an artist. For example, in the art development programs at Unilever or Siemens (Boyle and Ottensmeyer 2005) employees were invited to become artistic 
themselves, learning together with artists how to produce amateur works of art. Participation in the projects was voluntary, but with time there arose a core group of people for whom working in these ways became an important vehicle for noticing more about their work life.

In a different example, conductor Peter Hanke asks leaders to conduct a choir, and in the process has them closely examine and reconsider how they work with starting and stopping, timing, dynamic precision, thematic variation, synchronization, and vocal balance (Hanke 2005). When he asks them to start and stop a choral performance, they also compare their methods to instances of starting and stopping organizational activities. This engagement with different start/stop methods brings about a restless, multi-pointed sense of starting and stopping, which is surrounded and informed by an array of other possible ways and sensations. Executives come to be mindful of starting and stopping not because they are worried about what will happen if they don't, but because starting and stopping have become a source of fascination. In a similar fashion Frank Barrett uses jazz improvisation theory and a piano to have executives directly consider how they listen to and 'comp' (support) one another, interrupt habits, introduce variations, embrace errors, or leave gaps that others might want to plug into (Barrett 1998).

We have found that managerial intent in these projects often goes unstated. When pushed, however, managers tend to talk about heightened creativity, innovativeness, flexibility, and the like. Less frequently stated reasons are to make the daily organizational work more intrinsically motivating and enhance the organization's social worth. Perhaps this lack of clarity is a form of complicity for art to 'work' its results cannot be pinned down in advance, and thus when managers engage artists, it may be enough to know that they - both artist and manager - are after 'more than' and that knowing more than that will interfere with getting there.

Context Shifting. The workarts foster context shifting when artists analogically use their media to get employees to reconceive their work practices. Here the emphasis is not on discussing the art form, but on experiencing aspects of the workplace through another medium. In Europe, for example, choreographer Dorte Bille stages the movements of work processes, and organizational theatre companies in several countries perform organizational problems in front of organizational audiences (Meisiek 2004; Nissley et al. 2004).

The immediacy of such approaches is potentially heightened when organizational members co-create analogous artifacts. For example, choreographer Katrin Kolo has organizational members reconsider what leadership is by having them physically lead a group in various ways, e.g. from the front, side, center, and behind (cf. Denhardt and Denhardt 2005). Directors such as Piers Ibbotson (2008) use dramatic media to help employees re-present, rethink, and reformulate work issues, and a number of organizational theatre companies have sprung up across Europe, North America, and Australasia which provide participatory performances for organizations (Meisiek 2004; Meisiek and Barry 2007; Nissley et al. 2004).

On a larger scale, some European countries have sponsored long term, artist-led development initiatives (cf. Antal 2009) - the Airis project in Sweden (Lindqvist 2004; Styhre and Eriksson 2007), the NyX Innovation Alliance project in Denmark (Barry and Meisiek 2005), and the Disonancias project in Spain (Ramos 
2009). Airis organized 43 artist-company projects between 2003 and 2009, NyX organized 19 projects in 2004, and Disconancias organized 45 projects between 2007 and 2009 with variously sized business organizations in different industries. In these programs the focus was on developing creativity and improving innovativeness. After an initial period of problem definition, artists and managers had to work out particular ways of dealing with the problem and bring the company towards more interesting and commercially relevant solutions. The artists deliberately did not produce art for the organizations, but worked with employees on developing their sensibilities and reexamining their habitual modes of behavior and seeing through an art medium. The results varied widely, ranging from decorative additions to major organizational shifts.

An exemplar is a case from the Danish NyX project (Barry and Meisiek 2005). There, the painter Karsten Auerbach worked with Quilts (a company which makes duvets). He began by placing his easel in the center of the factory floor and painting the people and their operations. Every now and then an employee would walk past and ask questions about what he was painting. Around the same time, he went to a number of department stores to look at how the company's quilts were displayed. Coming back to the factory he confronted the managers: 'You're extremely white,' he said. 'There's no color in your product, your displays, or your work.' Managers later stated that they had never thought about their company in terms of color until that day. His next move was a workshop where employees mixed paints to form numerous color swatches. He asked 'Which one of these is Quilts?', a question which triggered intense and prolonged debate around just who and what the company was. This was followed by a photo collage workshop, where the employees used magazine cut-outs to represent the world of quilts. Their montage ranged from bluish photos which depicted technical advances, to warm coloured photos which connected quilts to comfort, happiness, and sex. As the implications of these experiments sank in, the company executives decided to change the business focus from technical superiority to more lifestyle considerations.

Regardless of their form, all these programs share a number of attributes. For one, the artistic media used brings organizational members away from their usual instrumental orientation and lets them edge closer to an artistic way of seeing. The media provide sensory feedback on the stakeholders' conceptual frameworks, which in turn may lead to mindfulness. Second, the work within artist-led interventions is usually pleasurable. As the pleasure of asking in one's work replaces the fear of asking, an emotional and cognitive buffer is formed. Third, with artist-led interventions people are asked to find unusual interpretations and meanings, ones that are normally not attached to what is being studied. This might help organizational members to break away from the categories that something belongs to and discover the meanings that something potentially attracts or allows (Meisiek and Hatch 2008).

\section{Artistic Experimentation}

'Can we do this on our own?' is the guiding question of the third workarts movement. When organizational members familiarize themselves with artistic 
thinking and media, there comes the question of whether they could forego formal artworks and artists, and foster mindfulness through artistic experimentation in their everyday work life. In our review, we found some initiatives that point towards a carefully affirmative answer. In particular, our sources suggest that fostering mindfulness through artistic experimentation requires a combinatorial practice, one that joins distinction making and context shifting.

A first step in this direction was to use art-like media without necessarily invoking the arts. For example, Barry (1994) had a group of senior army personnel sculpt their strategic issues with the help of tape, paper, paint, plastics, and other materials. This form of analogically mediated inquiry resulted in pronounced distinction making, surfaced a number of previously undiscussable issues, and ultimately led to substantial shifts in contextual understandings. Similarly, with the help of Lego blocks and sponsorship by the Lego company, the Imagination Lab in Lausanne conducted 'serious play' sessions with numerous organizations (Roos et al. 2004). Top managers would sit together and model their strategic landscape and organization using Lego bricks, coming up with representations that would promote more inventive strategic thinking. Likewise, the Center for Creative Leadership has had managers use organic materials to find, model, and develop their leadership roles (De Ciantis 1995). The goal of such initiatives has been to experiment with how mediating materials might help managers notice more about their organization, themselves, and find new understandings.

The experiments that De Ciantis, Roos et al. and Barry write about show that analogues need not come from outside the organization or be introduced by an artist; rather, they can be built by organizational members themselves. As such, they may lessen the 'not invented here' distancing that artist-led interventions such as Product \& Vision (Brellochs and Schrat 2005) can provoke.

Several researchers have investigated whether artistic ways of working can be applied in managerial settings. Howard Gardner's work on artistic thinking (1984), and Getzels and Csikszentmihalyi's (1979) studies of artistic creativity fall broadly into this camp. More specifically focused on management are Degot's (1989) thoughts on management as art, Austin and Devin's (2003) studies of iterative making in theatre and project management, Guillet de Monthoux's (2004) writings on art firms, Darso's (2004) review of art and business initiatives, Hatch, Kostera and Kozminski's (2007) work on leadership, Taylor and Carboni's (2008) discussion of performative arts in organizations, and Carroll and Flood's (2010) work on persuasive leadership and the arts. All these authors would claim that artistic thinking is not a mysterious property of the privileged few, but is something that can be learned and nurtured within organizational environments. This impulse comes from performative and conceptual art, where proponents advocate a deliberate rejection of art contexts and a turning to the artfulness of everyday lived experience (Whyte 1994; Booth 1997; Kaprow 2003). At the same time such practices are not easily or quickly acquired, as Taylor and Carboni (2008: 222) cogently point out:

On the one hand, art theory and criticism is based on propositional knowledge which is easily translated into text. Art practices, on the other hand, represent pragmatic knowledge which is not easily translated into text. Practice, in the arts as elsewhere, is historically learned through 'practical' hands-on experiences such as apprenticeships and studio models. Practice is learned through practice. 
We have identified a few instances where managers have used artistic processes and experiments to effect change in their organizations. We consider them artful, given that they partially embody some of the thinking and enactment that the professional art community uses, even though they were not intended as art. One is Dee Hock's legendary last minute casting and distributing of gold cufflinks to Visa's founding group - which had completely foundered. As Weick (2004: 38) notes, Hock stood before the group saying:

On one link is half of the world surrounded with the phrase 'the will to succeed' and the second link is the other half of the world and the phrase 'the grace to compromise.' We meet tomorrow for the final time to disband the effort after two arduous years. I have one last request. Will you please wear the cuff links to the meeting in the morning? When we part we will take with us a reminder for the rest of our lives that the world can never be united through us because we lack the will to succeed and the grace to compromise. (paraphrased from Hock, 1999, in Weick, 2004: 247-48)

Hock's staging was disruptive (the group was about to go home), surprising, and seriously humorous. It was also an act of distinction making and context shifting, particularly around the category of 'representing my interests' - something that is normally seen as a good thing. The stakeholders were forced to re-evaluate just what representing themselves entailed and to question the level at which they were working.

To illustrate how distinction making and context shifting potentially come together in artistic experiments, we offer an example of managerial artistry in an organization, originally published by Eirik Irgens (2000) and presented here in a shortened, translated version.

When Johnny Undeli became the new CEO of HAP-Raufoss, an aluminum smelting company that was facing bankruptcy, he used his first months to analyze productivity and market possibilities. He halved the number of top leaders, did away with privileges like company cars, and moved the executive parking lot outside the fence. After talks with the unions, the overall number of employees was also reduced. So far, nothing artful. Then, even though the company was still incurring heavy losses, he decided to spend a million Norwegian crowns - more or less the last of the company's money - to paint the production factory completely white, floors and all. The employees didn't know what to think. They were accustomed to not spending a cent unless the usefulness and economic rationality of the expenditure were fully documented. And the floor, walls and machines would soon be dirty and stained again. As it turned out, the employees focused more on order and cleanliness, which meant less time searching for tools and fewer production interruptions. They also saw their traces on the floors and machines, and began reconsidering their work patterns. Two years after the start of the change program HAP became one of the highest ranked companies in its industry.

What is noteworthy is the interplay of corporate crisis (going bankrupt and need to cut costs), distinction making (work processes on white paint), and context shifting (hospital white within a mining company). It was in the execution, artifact, and analogy that a deliberate break with the prevailing corporate rationality occurred. Usually a Norwegian crown could only be spent if an increase in efficiency was rationally predictable, whereas painting the factory suggested a 
leap-before-you-look logic. Combined with noticing their traditional practices on a white background, new interpretative possibilities were created. In effect Undeli gave the employees a white canvas on which to imagine what their factory could become. This example also suggests that artistic thinking is possible within a range of work conditions, not only in environments of surplus.

\section{Discussion}

Clearly, the workarts landscape has shifted considerably over the last few decades. All three domains - collection, intervention, and experimentation show how artistic ways of sensemaking and working have moved from something relegated to formal art institutions to the possibility of local 'small art' in the workplace (cf. Barry and Meisiek 2010; Davies 2007: 51-67). Within art collection, for instance, formal art collecting is being complemented by collections that matter locally. With respect to intervention, it used to be that artists were called into a company to create marketing-related artifacts. These days the growing tendency is for professional artists to help employees think artistically for themselves, again on a local basis. And relative to artistic experimentation, this appears to be increasingly conducted in locally referenced ways, sometimes autonomously, as we saw in the Undelli case, and frequently in assisted ways (Roos et al. 2004).

Why the shift from formal and institutionally detached to informal and locally embedded? Part of the reason could be the general shift towards experience economies and knowledge work, both of which place high premiums on the playful, imaginative mindfulness that we see in the workarts and which was described by Langer (2006). This perceived face validity of the workarts might also speak to a certain dissatisfaction with Weberian, Taylorist, and Fordist models of organization. The workarts represent the other side of a continuum between scientific approaches to organization and arts-based ones, and are possibly being popularized because they can complement and counterbalance efficiency-driven frameworks like TQM and ISO.

At the same time, we have seen that the workarts are a complicated business, and much can get masked by their rhetorical allure. Also, because they eschew close cause-and-effect inspection, the workarts' nature tends to go unexamined and can thus result in adoption decisions that may hinder more than help. Finding and theorizing the working mechanism behind the workarts is therefore a central concern of this paper. This brings us to a consideration of how and why the workarts work ... or do not.

There are at least two ways of thinking about the working of the workarts, one endogenous and the other more exogenous. From an endogenous perspective, our review suggests that the defamiliarizing relationship between work and workart is established and maintained with the help of analogous artifacts. Paintings, sculptures, sketches, performances, various art materials, etc., function in ways that are often identified as confusing or detrimental to organizing, e.g. deliberately disrupting performance-based movements, turning attention away from the work and towards the analogues, asking how the marginal, overlooked, 
and discarded can be center-staged, using more of the senses, and using associative processes to arrive at divergent understandings. We also saw that the creation and working of the analogous artifacts, under certain conditions, promotes mindfulness. This mindfulness is reached through a balancing of closeness and distance, and though a playful orientation. These aspects set workart initiatives apart from Weick, Sutcliffe and Obstfeld's (1999) work-focused mindfulness in high reliability organizations, where distance and playfulness would be regarded as dangerous.

Instead of saying 'look closely at what you're doing', analogous artifacts within the workarts say 'look at us while keeping your current situation in mind'. This looking elsewhere while attending to the current state of things requires a careful balancing of distance and closeness. If the relationship between the analogous artifact and work is too close, whereby the artifact appears overly ordinary, it will fail to catalyze novel distinctions or context shifts. And vice versa; if the artifact seems overly distant and/or exotic, the connection with work breaks and the artifact no longer promotes mindfulness. When the workarts work, a loose-but-not-too-loose connection is formed between an artifact's physical features (colour, shape, sound, etc.), potential analogies, and workplace understandings - where a given artifact can evoke multiple forms of analogizing as one revisits it. Hence, the analogizing is imprecise and unstable; a one-to-one mapping from source to target is not possible, nor is it desirable. What is desirable is a play between analogical possibilities.

This playful way towards mindfulness works because organizational members can make distinctions and shift contexts across the analogous artifact and workplace, and they can have distinction making and context shifting cross-inform each other through stimuli-driven and schema-driven interpretations. In the first case, creating or examining analogous artifacts and thinking make it possible to address and extend existing schemata, ones which would resist change efforts if dealt with directly (e.g. Smith and Simmons 1983). In the second case, any analogical relationship established between artifact and workplace can be reexamined by attending to different stimuli provided by the artifact. This means that analogous artifacts work simultaneously at the level of schemata, evoked though the analogy, and at the level of stimuli, via the physical and performative nature of the artifact. The various cues given by the artifact, e.g. the 'Competitor's Blue House' example in the introduction, invite a reformulating and expanding of the analogy taken up so far. Conversely, the analogies made allow the organizational members to re-interpret various stimuli of the artifact. The goal of these playful interpretative moves is to see more, see differently, and to allow organizational members to make interpretative extensions regarding their workplace scripts, categories, and schemas.

This playfulness around mindfulness highlights for the organizational members that there is more than one way to frame a problem or question and more than one solution to a given problem. The workarts' emphasis on making the familiar strange encourages organizational members to accept the overlooked, weak, and marginal in their work environments as possible aides. In this way, analogous artifacts can help organizational members to comfortably hold and behold uncertainty and ambiguity, as well as suggesting new developmental paths. 
The workarts have no stopping rules. The artifacts can always evoke further analogical relationships, and ever more aspects can be revisited in their light. However, there seems to be a point of saturation. When employees feel that they have covered some ground, and are mindfully aware of what is going on at their workplace again, they tend to stop working with the analogous artifact. The artifact can then either be destroyed, as in the end of the Lego-based artistic experimentation (Roos et al. 2004), or it might become a symbol of workplace identity, as in the Øvlisen case (Aunstrup et al. 2000).

At the end of the workarts initiative, territory discovered through distinction making needs to be linked back to what is already known and sensed. And when contexts are shifting, organizational members must reconstruct their ontological security, making the unusual normal. This means that organizational members need to balance the mindfulness and mindlessness that the two imply with the associated costs and benefits of doing so.

According to Levinthal and Rerup (2006), balancing acts happen around repertoires of action, processes for sustaining mindfulness, routines, and the encoding of ambiguous outcomes. Within each process, both mindfulness and less mindful behaviors have their place. Similarly, we argue that analogous artifacts support the development of repertoires of action through distinction making and context shifting, but it is also up to organizational members to sustain them.

Our review suggests that these endogenous workings of the workarts are influenced by 'slack'. By slack, we broadly mean excess resources - the morethan-is-needed to do the job. Such resources can come in many forms, ranging from financial liquidity to patience, and imaginativeness to receptivity. As slack increases, different things might happen. One is a leaning towards formal art collection, particularly where there is financial surplus and executive stakeholders are looking for investments. As we noted earlier, this may in turn lead to a kind of complacency, where the perceived separation between art displays and work increases and distinction making and context shifting around work routines decreases. Alternatively, increased slack may let more unusual workarts practices through the door, ultimately leading to more mindfulness. The Unilever example is relevant here, where the company's investment in arts training for employees apparently enhanced overall organizational imaginativeness and change (Boyle and Ottensmeyer 2005).

The opposite can also occur under high slack - the workart engagement becomes remembered as yet another entertainment event, corporate vacation, or write-off. In highly mindful companies for instance, arts-based distinction making or context shifting exercises might be seen as trivial and unnecessary extensions to what is already being done. Managers may find that the art encounters only yield marginal gains in attention.

Low slack, on the other hand, is likely to drive workarts adopters towards direct artistic experimentation, particularly where executives have their backs against the wall and feel there is nothing to lose - the Undelli case for example. At the same time, low slack means being unable to afford meandering considerations of artistic merit. We propose that in such circumstances, relevance and artifactual 'grab' will become of utmost importance. 
Workarts initiatives under low slack may also fail because employees do not want art at work - they want to work without distractions and then choose their own forms of artistic engagement when they are off work. This might be especially true where the workarts too closely reflect managerial imperatives that have already been rejected by non-management; thus to become involved with them signals acquiescence. A number of the activities reviewed here fall into this camp, e.g. Clark and Mangham's (2004) paper on organizational theater, where corporate theater events are described as sophisticated forms of corporate compliance seeking and brain-washing.

Collectively, these observations suggest the need for more longitudinal, comparative research. Everything we have noted around how the workarts and their analogous artifacts do and don't work is still highly conjectural and based mostly on anecdotal evidence. Given the variance in our findings, we suggest that those writing in the field try to avoid sweeping, non-critical generalizations. Even though the anecdotes sometimes add up, they are still no substitute for comprehensive, comparative, and long-term evaluative research. Tsoukas and Chia's (2002) proposal to use ethnographic research in addition to text-based analysis seems quite fitting here, as do qualitative evaluation methodologies (cf. Patton 2001). Also, while contemporary artists tend to avoid considerations of aesthetics, we think that examining the workarts from an aesthetics perspective (Strati 1999; Lindstead and Höpfl 2000; Taylor and Hansen 2005) could help shed more light on why workart initiatives are taken up. We would also welcome more quantitative studies of the field, ones similar to Getzels and Czikszentmihalyi's (1979) studies of arts-based creativity.

\section{Conclusion}

If organizational members only focus on the task at hand, they may become bored, tired, and feel like life is drained from them (Terkel 1997). They may fashion detours and games just to keep things a little interesting (Roy 1959). This has usually led managers to conjure up new forms of managerial control with the idea that if every detail is known and every action accounted for, organizational members will stay focused on the task at hand. This downward spiral towards the lifeless workplace has been countered in some organizations through involvement with artful analogous artifacts. These potentially invite detours that are not only good for overcoming the doldrums of work, but for mindfulness and richer sensemaking in organizations. Yet they are clearly no panacea.

Whither the workarts or wither the workarts? This is the final question we're left with. Will the workarts form a rich main course, a regular yet distinctive part of what organizational members consume and digest? Will they become a less regular yet sought after hors d'oeuvre or accompaniment? Or will they wither away altogether, surrounded by fond adieus or damning curses? Much depends on the directions the field takes from here. If it continues to stake out the 'meaningfulness' territory, an area where it is particularly adept, and if its scholars begin to utilize more comparative and evaluative methods, things may go well. 
Conversely, if the field relies on sensationalism and glittery rhetoric to make its points, concentrates solely on anecdotal evidence, and makes overly inflated claims, withering away is the more likely outcome. We're hoping that those in the field will opt for the steeper climb with its correspondingly finer views.

\section{References}

Andersen, Christine B., and Kent Hansen 2001 Visionsindustri. Viborg: Vestsjaellands Kunstmuseum Informations Forlag.

Ansoff, Igor

1975 'Managing strategic surprise by response to weak signals'. California Management Review 18/2: 21-33.

Antal, Ariane B.

2009 Transforming organizations with the arts. Berlin: WZB Research Report.

Aunstrup, Knud, Malene Rasmussen, Lise Øvlisen, and Annemette Fisher (eds)

2000 You do not have to like the art you see at Novo Nordisk, but I hope it makes you stop and ask a few questions. Bagsvaerd, Denmark: Novo A/S.

Austin, Rob, and Lee Devin

2003 Artful making. Upper Saddle River, NJ: FT Prentice Hall.

Barrett, Frank J.

1995 'Creating appreciative learning cultures'. Organizational Dynamics 24/2: 36-49.

Barrett, Frank J.

1998 'Creativity and improvisation in jazz and organizations: Implications for organizational learning'. Organization Science 9/5: 605-622.

Barry, Daved

1994 'Making the invisible visible: Symbolic means for surfacing unconscious processes in organizations'. Organizational Development Journal 12: 37-48.

Barry, Daved

1996 'Artful inquiry: A symbolic constructionist approach to social science research'. Qualitative Inquiry 2: $411-438$.

Barry, Daved, and Stefan Meisiek

2005 NyX Innovation Alliance Evaluering. Unpublished report.

Barry, Daved, and Stefan Meisiek

2010 'The art of leadership and its fine art shadow'. Leadership. (forthcoming)

Bartelme, Lois

2005 'The view from the trenches: An interview with Harvey Seifter and Tim Stockil'. Journal of Business Strategy 26/5: 7-13.

Bartunek, Jean M.

2007 'Academy arts: The genesis, birth, short life, and death of an innovation'. Journal of Management Inquiry 16: 94-98.

Behnke, Christoph

2007 'Corporate art collecting: A survey of German-speaking countries'. The Journal of Arts Management, Law, and Society 37/3: 225-243.

Booth, Eric

1997 The everyday work of art. Chicago: Sourcebooks Inc.

Boyle, Mary-Ellen, and Edward Ottensmeyer 2005 'Solving business problems through the creative power of the arts: Catalyzing change at Unilever'. Journal of Business Strategy 26/5: 14-21.

Breitwieser, Sabine (ed.)

1995 Andrea Fraser. Report: EA-Generali Foundation. Wien: Generali Foundation.

Brellochs, Mari, and Henrik Schrat (eds)

2005 Product \& vision: An experimental set-up between art and business. Berlin: Kulturverlag Kadmos.

Buswick, Ted

2005 'Seeing your audience through an actor's eyes: An interview with George Stalk'. Journal of Business Strategy 26/5: 22-28.

Buswick, Ted, and Harvey Seifter (eds)

2005 'Arts-based learning for business; Special Issue'. Journal of Business Strategy 26/5.

Carlile, Paul

2002 'A pragmatic view of knowledge and boundaries: Boundary objects in new product development'. Organization Science 13/4: 442-455.

Carroll, Stephen, and Patrick Flood 2010 The persuasive leader: Lessons from the arts. Chichester: John Wiley \& Sons. 
Clark, Timothy, and Ian Mangham

2004 'Stripping to the undercoat: A review and reflections on a piece of organization theatre'. Organization Studies 25/5: 841-851.

Cornelissen, Joep

2004 'What are we playing at? Theatre, organization and the use of metaphor'. Organization Studies 25: 705-736.

Craft, Mary A.

1979 'The corporation as art collector'. Business Horizons 22/3: 20-25.

Darsø, Lotte

2004 Artful creation: Learning-tales of arts-in-business. Copenhagen: Samfundsliteratur.

Davies, Stephen

2006 'Aesthetic judgments, artworks, and functional beauty'. Philosophical Quarterly 56: 224-241.

Davies, Stephen

2007 Philosophical perspectives on art. Oxford: Oxford University Press.

Day, George, and Paul Schoemaker

2004 'Driving through the fog: Managing at the edge'. Long Range Planning 37/2: 127-142.

De Ciantis, C.

1995 Using an art technique to facilitate leadership development. Spring Lake, MI: Center for Creative Leadership.

Degot, Vincent

1989 'Portrait du gestionnaire en artiste (Portrait of the manager as an artist)'. Information sur les Science Sociales 18/1: 215-231.

Denhardt, Robert B., and Janet V. Denhardt

2005 The dance of leadership: The art of leading in business, government, and society. Armonk, NY: M.E. Sharpe.

Dyson, Stephen B., and Thomas Preston

2006 'Individual characteristics of political leaders and the use of analogy in foreign policy decision making'. Political Psychology 27/2: 265-288.

Ferro-Thomsen, Martin

2005 'Change through exchange: Organisational art and learning' in Sophisticated survival techniques: Strategies in art and economy. M. Brellochs and H. Schrat (eds), 183-197. Berlin: Kultureverlag Kadmos.

Gadamer, Hans-Georg

1986 The relevance of the beautiful and other essays. Cambridge: Cambridge University Press.

Gardner, Howard E.

1984 Art, mind and body. New York: Basic Books.

Gavetti, Giovanni, and Daniel Levinthal

2000 'Looking forward and looking backward: Cognitive and experiential search'. Administrative Science Quarterly 45/1: 113-137.

Getzels Jacob W., and Mihaly

Czikszentmihalyi

1979 The creative vision. New York: John Wiley \& Sons.

Gibson, Cristina B., and Mary E. Zellmer-

Bruhn

2001 'Metaphors and meaning: An intercultural analysis of the concept of teamwork'. Administrative Science Quarterly 46: 274-303.

Gioia, Dennis A., and Kumar Chittipeddi

1991 'Sensemaking and sensegiving in strategic change initiation'. Strategic Management Journal 12: 433-448.

Gioia, Dennis A., and James B. Thomas

1996 'Identity, image, and issue interpretation: Sensemaking during strategic change in academia'. Administrative Science Quarterly 41/3: 370-403.

Guillet de Monthoux, Pierre

2004 The art firm. Stanford: Stanford University Press.

Hanke, Peter

2005 'Kreativitet kan ikke anskaffes - det skal læres'. Ledelse i Dag 61: 32-36.

Harris, Craig (ed.)

1999 Art and innovation: The Xerox PARC artist-in-residence program. Cambridge, MA: MIT Press.

Hatch, Mary J., Monica Kostera, and Andrzej Kozminski

2007 The three faces of leadership: Manager, artist, priest. Hoboken: Wiley-Blackwell.

Heidegger, Martin

1975 Poetry, languages, thought. New York: Harper and Row.

Hill, Robert C., and Michael Levenhagen

1995 'Metaphors and mental models: Sensemaking and sensegiving in innovative and entrepreneurial activities'. Journal of Management 21: 1057-1074. 
Hock, Dee

1999 Birth of the chaordic age. San Francisco: Berret-Koehler.

Ibbotson, Piers

2008 The illusion of leadership. Houndmills: Macmillan.

Irgens, Eirik J.

2000 Den dynmiske organisasjon. Oslo: Abstrakt.

Jacobson, Marjory

1993 Art for work: The new renaissance in corporate collecting. Boston: Harvard Business School Press.

Kaprow, Alan

2003 Essays on the blurring of art and life. Berkeley: University of California Press.

Keil, Martin, and Henrik Meyer

2008 Reinigungsgesellschaft: Project proposals of six visual artists Learning workshop for art and the economy. Dresden: Sächsischer Künstlerverband.

Ladkin, Donna, and Steve Taylor

2009 'Understanding arts-based methods in managerial development'. Academy of Management Learning and Education 8/1: 55-69.

Lakoff, George, and Mark Johnson

1980. Metaphors we live by. Chicago: University of Chicago Press.

Langer, Ellen J.

1989 Mindfulness. Reading, MA: Addison Wesley.

Langer, Ellen J.

2006 On becoming an artist: Reinventing yourself through mindful creativity. New York: Ballentine Books.

Langer, Ellen J., and Mihnea Moldoveanu 2000 'The construct of mindfulness'. Journal of Social Issues 56/1: 1-9.

Levinthal, Daniel, and Claus Rerup

2006 'Crossing an apparent chasm: Bridging mindful and less-mindful perspectives on organizational learning'. Organization Science 17/4: 502-513.

Lindqvist, Katja

2004 Att göra de främmande till sitt. Unpublished report.

Linstead, Steven, and Heather Höpfl (eds)

2000 The aesthetics of organization. London: Sage.

Made, Caroline

2004 Contemporary patronage: Corporate art collecting. Unpublished masters thesis.

Martorella, Rosanne

1990. Corporate art. New Brunswick: Rutgers University Press.

Medical Yale

2006 'Yale innovation in the art of observation extends its reach'. Medical Yale 2/2: 10.

Meisiek, Stefan

2004 'Which catharsis do they mean? Aristotle, Moreno, Boal and organization theatre'. Organization Studies 25/5: 797-816.

Meisiek, Stefan, and Daved Barry

2007 'Through the looking glass of organizational theatre: Analogically mediated inquiry in organizations'. Organization Studies 28: 1805-1827.

Meisiek, Stefan, and Mary J. Hatch

2008 'This is work, this is play' in The SAGE Handbook of New Approaches in Management and Organization. D. Barry and H. Hansen (eds), 412-422. London: Sage.

Mirvis, Philip

2008 'Executive development through consciousness-raising experiences'. Academy of Management Learning and Education 7/2: 173-188.

Mirvis, Philip, Karen Ayas, and George Roth 2003. To the desert and back. San Francisco: Jossey-Bass.

Nicholsen, Louise, and Alistair R. Andersen

2005 'News and nuances of the entrepreneurial myth and metaphor'. Entrepreneurship Theory \& Practice 29: $153-172$.

Nissley, Nick

1999 Viewing corporate art through the paradigmatic lens of organizational symbolism: An exploratory study. Unpublished doctoral dissertation. Washington, DC: The George Washington University.

Nissley, Nick, Steve S. Taylor, and Linda Houden

2004 'The politics of performance in organizational theatre-based training and interventions'. Organization Studies 25: 817-839.

Olivier, Richard, and Julie Verity

2008 'Rehearsing tomorrow's leaders: The potential of mythodrama'. Business Strategy Series 9/3: 138-143. 
Patton, Michael Q.

2001 Qualitative research \& evaluation methods, 3rd edn. Thousand Oaks: Sage.

Ramos, Ana

2009 Dissonancias. Unpublished report.

Rerup, Claus

2009 'Attentional triangulation: Learning from unexpected rare crisis'. Organization Science 20/5: 876-893.

Roos, Johan, Bart Victor, and Matt Statler 2004 'Playing seriously with strategy'. Long Range Planning 37: 549-568.

Roy, Donald F.

1959 'Banana time: Job satisfaction and informal interaction'. Human Organization 18: 158-168.

Schein, Edgar H.

2001 'The role of art and the artist'. Reflections 2/4: 81-83.

Schrat, Henrik

2000 Die Erscheinung der Phantasie. Dresden: Verlag der Kunst.

Scotese, Peter G.

1978 'Business and art: A creative, practical partnership'. Management Review 67/10: 20-25.

Seifter, Harvey

2005 'Surfacing creativity through the arts: A short interview with Terry McGraw'. Journal of Business Strategy 26/5: 6.

Semler, Ricardo

2004 The seven-day weekend: Changing the way work works. New York: Warner Books.

Shklovsky, Victor

2004 'Art as technique' in Literary Theory: An Anthology. Julie Rivkin and Michael Ryan (eds.), 15-21. Hoboken: Wiley-Blackwell.

Smith, Kenwyn K., and Valerie M. Simmons

1983 'A Rumpelstilskin organization: Metaphors on metaphors in field research'. Administrative Science Quarterly 28: 377-392.

Strati, Antonio

1999 Organization and aesthetics. London: Sage.

Styhre, Alexander, and Michael Eriksson

2007 'Bring in the arts and get the creativity for free: A study of the Artists in Residence project'.
Creativity and Innovation

Management 16/4: 47-57.

Svejenova, Silviya, Carmelo Mazza, and Marcel Planellas

2007 'Cooking up change in haute cuisine: Ferran Adrià as an institutional entrepreneur'. Journal of Organizational Behavior 28/5: 539-561.

Taylor, Steve S., and Inga Carboni

2008 'Technique and practices from the arts' in The SAGE Handbook of New Approaches in Management and Organization. D. Barry and H. Hansen (eds), 220-228. London: Sage.

Taylor, Steve S., and Hans Hansen

2005 'Finding form: Looking at the field of organizational aesthetics'. Journal of Management Studies 42/6: 1211-1231.

Terkel, Studs

1997 Working: People talk about what they do all day and how they feel about what they do. New York: New Press.

Toma, Yann, and Rose Marie Barrientos

2008 Les enterprises critiques - Critical companies. St Etienne: Cité du Design Editions.

Tsoukas, Haridimos, and Robert Chia

2002 'On organizational becoming: Rethinking organizational change'. Organization Science 13/5: 567-582.

Turkle, Sherry

2007 Evocative objects: Things we think with. Cambridge, MA: MIT Press.

Velthuis, Olaf

2005 Imaginary economics. Rotterdam: NAI.

Walker, John A.

1995 John Latham: The incidental personhis art and ideas. London: Middlesex University Press.

Weber, Klaus, and Mary Ann Glynn

2006 'Making sense with institutions: Context, thought and action in Karl Weick's theory'. Organization Studies 27/11: 1639-1660.

Weick, Karl E.

1995 Sensemaking in organizations. Newbury Park, CA: Sage.

Weick, Karl E.

2002 'Puzzles in organizational learning: An exercise in disciplined 
imagination'. British Journal of Management 13: S7-S15.

Weick, Karl E.

2004 'Rethinking organizational design' in Managing as designing. Richard J. Bolland and Fred Callopy (eds), 36-53. Stanford, CA: Stanford University Press.

Weick, Karl E., and Kathleen Sutcliffe 2006 'Mindfulness and the quality of organizational attention'. Organization Science 17/4: 514-524.

Weick, Karl E., Kathleen Sutcliffe, and David Obstfeld

1999 'Organizing for high reliability: Processes of collective mindfulness' in Research in organizational behaviour, Vol. 21. Barry M. Staw and Robert I Sutton (eds), 81-123. Stamford, CT: JAI Press.

Weick, Karl E., Kathleen Sutcliffe, and David Obstfeld

2000 'High reliability: The power of mindfulness'. Leader to Leader 17: 33-38.

Weick, Karl E., Kathleen Sutcliffe, and David Obstfeld

2005 'Organizing and the process of sensemaking'. Organization Science 16/4: 409-421.
Whyte, David

1994 The heart aroused: Poetry and the preservation of the soul in corporate America. New York: Doubleday Business.

Wijnberg, Nachoem M., and Gerda Gemser 2000 'Adding value to innovation: Impressionism and the transformation of the selection system in visual arts'. Organization Science 11/3: 323-329.

Wilson, Ian, and William Ralston

2006 Scenario planning handbook: Developing strategies in uncertain times. Mason, $\mathrm{OH}$ : Thompson Publishing.

Wright, Charles R., Michael R. Manning, Bruce Farmer, and Brad Gilbreath

2000 'Resourceful sensemaking in product development teams'. Organization Studies 21/4: 807-825.

Wu, Chin-Tao

2002 Privatizing culture: Corporate art intervention since the 1980s. London: Verso.

Zander, Rosamund S., and Benjamin Zander 2000 The art of possibility: Transforming professional and personal life. Cambridge, MA: Harvard Business School Press.

\section{Daved Barry}

Stefan Meisiek
Daved Barry is Professor of Creative Organization Studies in the Department of Management, Politics and Philosophy at the Copenhagen Business School, and Visiting Professor at Nova SBE (Universidade Nova de Lisboa School of Business and Economics). He has studied music, painting, chemistry, and cooking, eventually going on to complete a BA (hons) in Psychology and a PhD in Strategic Management and Organizational Psychology at the University of Maryland. His work focuses on how art, design, and narrative thinking can inform and improve organizing, problem solving, managing, and leadership.

Address: Copenhagen Business School, Porcelaenshaven 18B, 2000 Frederiksberg, Denmark.

Email:db.lpf@cbs.dk

Stefan Meisiek is Associate Professor of Leadership at the Copenhagen Business School, and Visiting Professor at Nova SBE (Universidade Nova de Lisboa School of Business and Economics). He received his $\mathrm{PhD}$ in Management from the Stockholm School of Economics and his MA from the Free University, Berlin. He has been a visiting scholar at NYU Stern, ESADE, Stanford University, and MIT Sloan. His research interests concern mainly ideation, entrepreneurial reasoning, and arts-based approaches to problem solving and organizing.

Address: Copenhagen Business School, Porcelaenshaven 18B, 2000 Frederiksberg, Denmark.

Email: sm.lpf@cbs.dk 


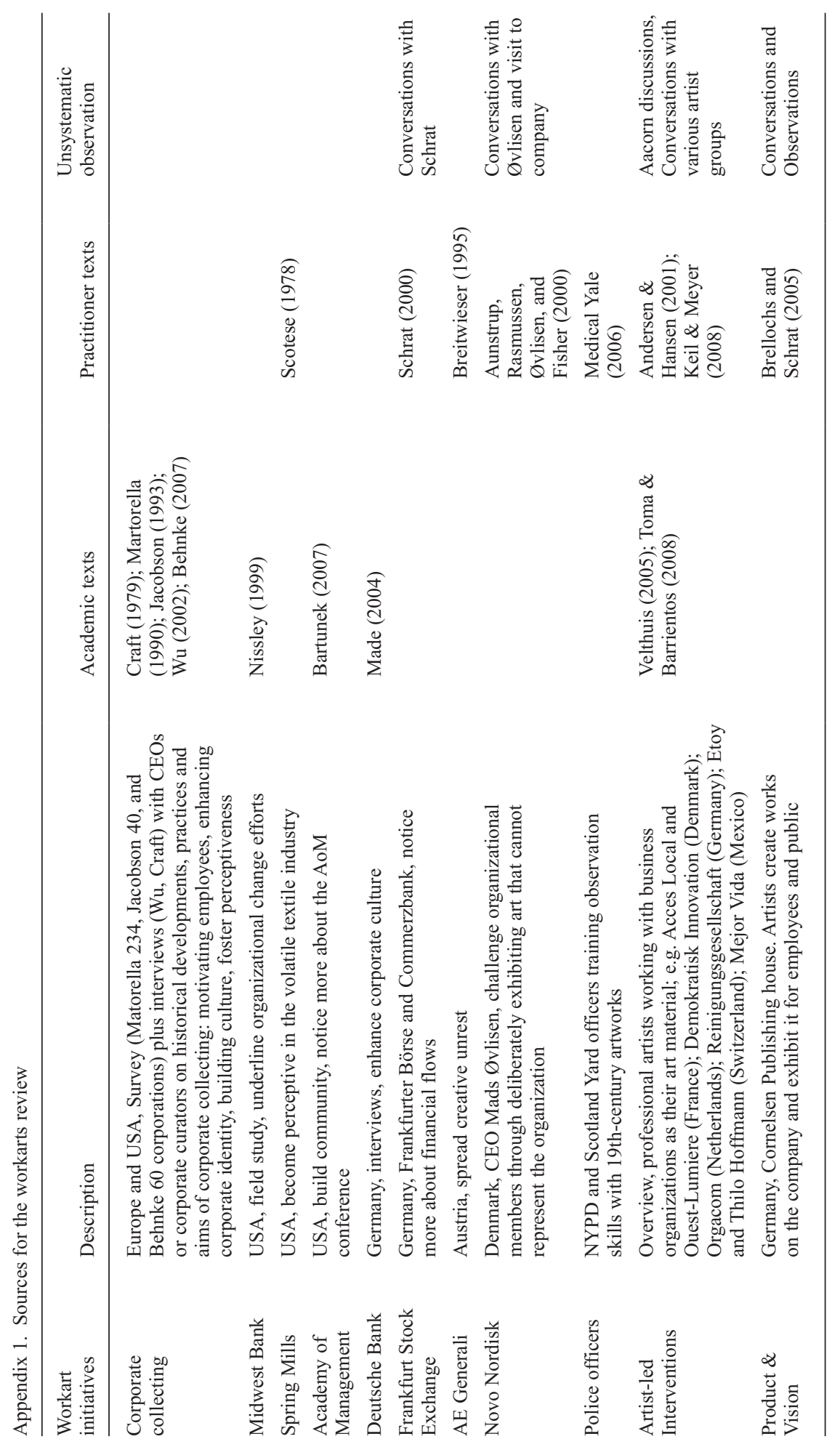




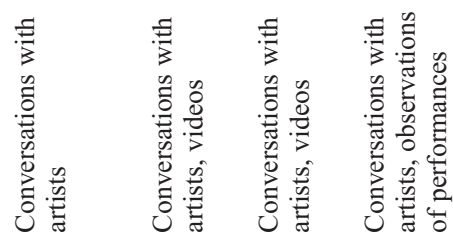

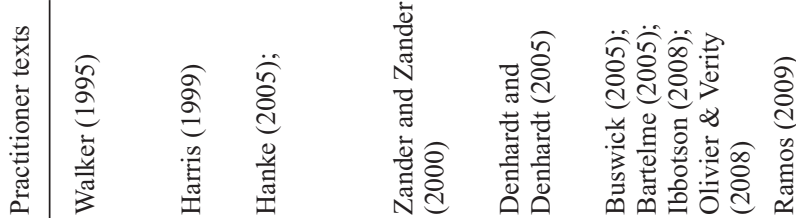

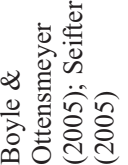

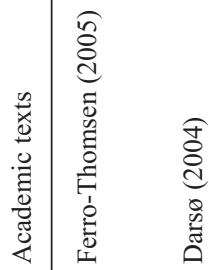
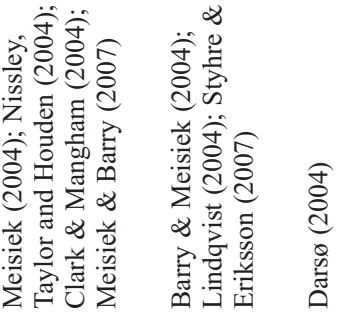

\%

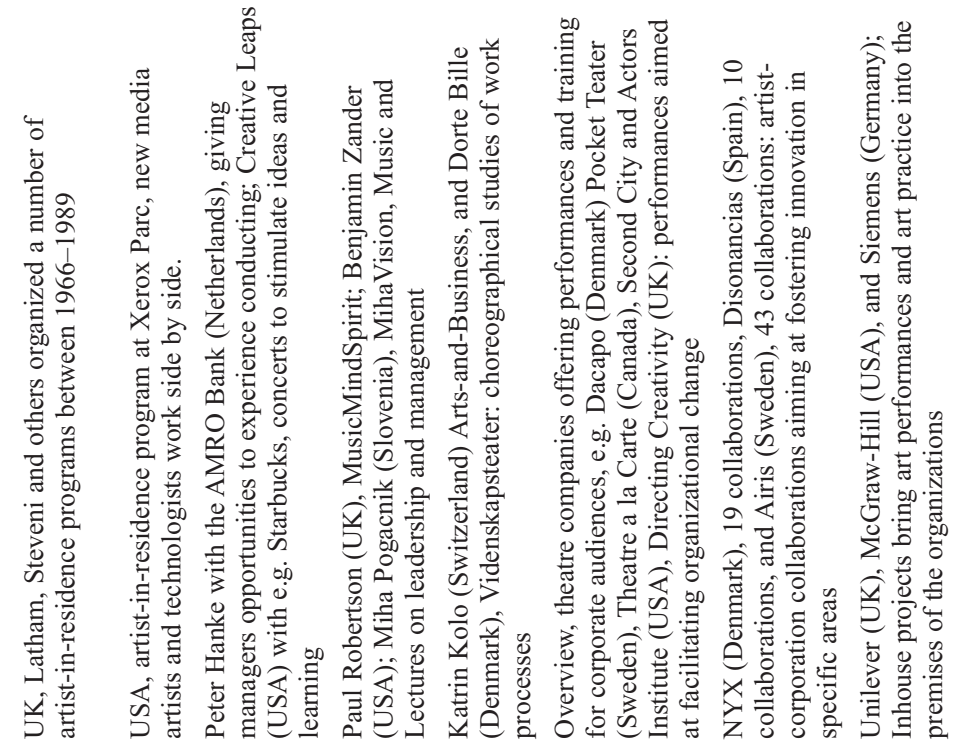

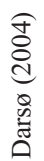

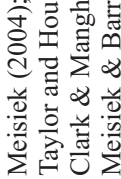

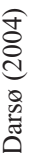

䨓

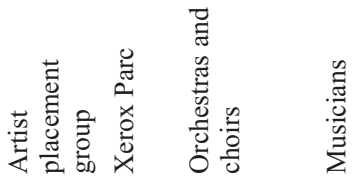

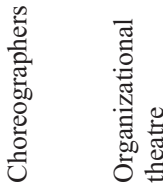
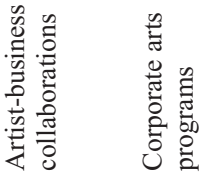


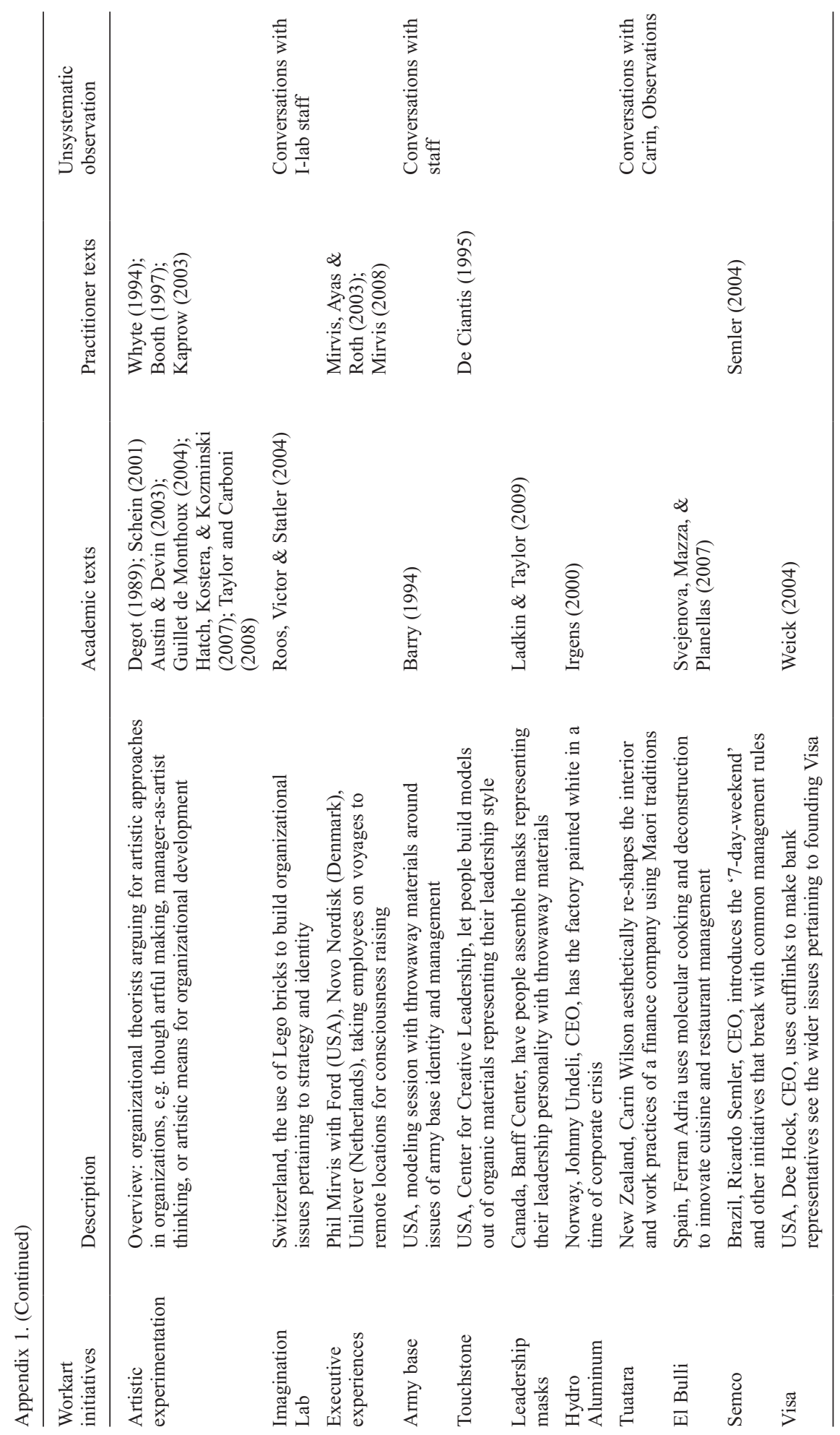

